\title{
ATUALIDADE/NECESSIDADE DO PENSAMENTO DE PAULO FREIRE: A EXPERIÊNCIA DA PRÁTICA DOCENTE EM UM CURSINHO POPULAR
}

\author{
POR ANGÉLICA DE LUCA' \\ MARÍA ELENA INFANTE-MALACHIAS ${ }^{2}$
}

\section{RESUMO}

Neste artigo, apresentamos uma interpretação à luz do pensamento de Paulo Freire sobre a prática de um cursinho popular localizado na cidade de Itapevi, região periférica da grande São Paulo. As práticas desses cursinhos podem reatualizar o pensamento de Paulo Freire e preservá-lo do esquecimento ou da ruína de leituras distorcidas e equivocadas. $\bigcirc$ estudo realizado a partir de um grupo focal com quatro professores voluntários revelou que estes professores, embasados em uma concepção de educação para além do que é "possível", propõem e oferecem uma formação humana crítica aos seus estudantes, questionam a própria prática educativa e o vestibular. A educação popular desenvolvida nos cursinhos populares, além de atualizar a relevância político-pedagógica do pensamento de Paulo Freire, torna-se cada vez mais urgente e necessária para que se consolide uma verdadeira cultura democrática.

\section{PALAVRAS-CHAVE}

Cursinho Popular, Pedagogia Freireana,

Conscientização.

\begin{abstract}
College Preparatory popular courses are being created in Brazil's peripheries in order to help poor young people to have a chance to compete for higher education positions. In this article we present an interpretation in the light of the thought of Paulo Freire on the practice of a popular course located in Itapevi, a city located at the peripheral region of the great São Paulo. The question that moves us is: could the practices of these courses rescue Freire's thinking for the present and preserve it from the oblivion of the ruin of distorted readings? The speeches obtained at the focus group meeting with four volunteer teachers revealed that these teachers, based on a conception of education beyond what is "possible", offer a critical human formation to their students, these teachers question their own educational practices and their own entrance exam. Popular education developed in the popular curriculum updates the pedagogical and political relevance of Paulo Freire's proposals.
\end{abstract}

\section{KEYWORDS}

Accessible Preparatory Courses, Freire's Pedagogy, Awareness.

\footnotetext{
1 Angélica de Luca é licenciada em Ciências da Natureza pela Escola de Artes, Ciências e Humanidades (EACH-USP) e mestranda do programa de Pós Graduação da FEUSP. Atualmente trabalha como professora na rede municipal de ensino de São Paulo.

${ }^{2}$ María Elena Infante-Malachias é professora livre docente da Escola de Artes, Ciências e Humanidades (EACH- USP) e orientadora pelos programas de Pós Graduação: Interunidades em Ensino de Ciências e de Educação da FEUSP.
} 


\section{Introdução}

A inquietação que move esse caminho de pesquisa é dada pela indignação e revolta diante da miséria e exploração que assola o mundo através da reprodução de mecanismos de exclusão e segregação. Estamos certos de que reconhecer os valores e convicções que nos orientam em nossos caminhos de pesquisa é, sem dúvida, o que garante a objetividade da pesquisa social.

Vivemos na era da desconfiguração do Estado como assegurador mínimo do acesso aos direitos sociais, na era do esvaziamento da política, do governo dos tecnocratas gestores do bem comum a serviço da irracionalidade do sistema econômico, era em que o aprofundamento da miséria de muitos é condição para a concentração da riqueza de poucos. A perversidade do fato de que o $1 \%$ mais rico detenha mais riqueza que o resto do mundo é angustiante. Soma-se a isso a fragilidade de nosso planeta, constatada por diversas pesquisas que nos alertam sobre os impactos ambientais irreparáveis inerentes ao modo de vida irresponsável e vazio de sentido que se funda na exploração irrestrita (DOWBOR, 2017).

Tal irracionalização do sistema de organização social a que nos submetemos gera problemas gravíssimos cujas responsabilização e reparação não são possíveis, posto que, muito mais do que um grupo de seres humanos malévolos praticando crueldade, trata-se de sistema sem rosto e sem controle que se redesenha e nos condiciona, alastra-se e se reproduz através de mecanismos intrincados entre si, com o propósito de nos incutir valores que, quando assimilados e interiorizados em nosso fazer cotidiano, garantem a perpetuação da ordem social vigente.

Sendo um sistema que nos transpassa, só pode se realizar penetrando nossa cultura e nossa educação. Não haveria como se manter, se sustentar e se reproduzir se não houvesse, através do Estado, um mecanismo de transmissão dos valores e princípios, um mecanismo que controle nossa orientação no mundo, velando a realidade, os conflitos, as contradições e, sobretudo, silenciando qualquer discurso que possa despertar uma prática social solidária e autônoma, reprimindo os exemplos novos e apagando a memória dos exemplos do passado.

O nosso país, lamentavelmente, ocupa lugar de destaque mundial no 
que se refere à concentração de renda. Nosso duradouro passado escravocrata nos deixou profundamente marcados pela desigualdade e pela lógica da exploração. Jessé Souza (2012) defende que as sociedades modernas periféricas, como o Brasil, se diferenciam das sociedades modernas centrais porque seu processo histórico de formação assegurou que um grandioso número de pessoas permanecesse completamente apartado de direitos. Muito embora essas pessoas possam estar economicamente ativas, sobretudo no mercado informal, elas não têm acesso sequer aos direitos básicose, na condição de exploradas, conseguem somente a manutenção da própria existência. A essa massa, Jessé Souza (2012) provocativamente chama de ralé, evidenciando que ela corresponde a um terço da população brasileira. (SOUZA, 2012)

Todos esses brasileiros e brasileiras que fazem parte desse um terço da população chamado de ralé estão inseridos numa lógica de exploração que os adoece, que os distancia do convívio familiar, da cidade onde residem, da convivência na comunidade, posto que a lógica do mercado consome a força e o tempo dessas pessoas e os converte em poder de consumo para uns poucos privilegiados. A pergunta que fazemos é: Como é possível para essa parcela gigantesca da população escapar desse ciclo perpétuo de consumo da vida? Como é possível escapar da exploração e ter experiências na ação coletiva?

Para nós, a escola pública é um dos espaços em que se tornam possíveis a experiência e a ação, justamente porque nela meninos e meninas são resgatados da lógica da exploração e podem ter alguns anos da vida dedicados à leitura e à compreensão do mundo - apesar de sabermos que a educação é também um mecanismo de introjeção de valores legitimadores da ordem social vigente (MESZÁROS, 2008) e que, assumindo um caráter institucional, reflete em si a forma que tem o Estado e sustenta os interesses deste.

Paulo Freire nos apresentou uma proposta de educação que leva em consideração a estrutura de dominação característica das sociedades dependentes, com o objetivo de enfrentar essa realidade. Segundo ele, uma transformação das estruturas, apenas, não é possível nem válida, se não for acompanhada nem precedida de uma verdadeira liberação das consciências (GARCÍA-HUIDOBRO, 
2005). Sua proposta educacional é fundada na busca da consciência crítica de cada ser humano no sentido de sua libertação da condição de explorado. Portanto, a educação, para Paulo Freire, está inserida em um cenário de profunda desigualdade e neste cenário a educação deve promover a transformação dessa realidade desigual em oportunidade para todos os sujeitos. Ainda que reconheça que essa transformação não se daria apenas pela educação, Paulo Freire assume que ela tem papel fundamental na sociedade, sobretudo porque possibilita aos jovens que enxerguem outros horizontes de possibilidades para além de reproduzir o papel que Ihe foi herdado na reprodução do sistema social.

Sobre a consciência das condições de desigualdade, Jessé Souza (2012) afirma:

A meus olhos, é a circunstância da "naturalização" da desigualdade periférica que não chega à consciência de suas vítimas, precisamente porque construída segundo as formas impessoais e peculiarmente opacas e intransparentes, devido à ação, também no âmbito do capitalismo periférico, de uma "ideologia espontânea do capitalismo" que traveste de universal e neutro o que é contingente e particular. (SOUZA, 2012, p.180)

Os projetos de expansão do ensino superior no Brasil a partir de 2002 contribuíram significativamente para que os jovens das periferias ousassem sonhar com a ampliação dos estudos. Ainda que os programas tenham privilegiado essa expansão pela via privada, trata-se, sem dúvidas, de um passo importante na democratização da educação no país. De acordo com o que Bourdieu conceitua como habitus (SETTON, 2002), esse público que chega às universidades a partir do processo de democratização da educação no Brasil se difere do que se costuma revelar dentro dessas instituições elitizadas, sobretudo nas universidades públicas. Com o discurso pretenso da defesa da qualidade, muitos se opõem aos processos de democratização, justamente pela inquietação social que provoca nas classes mais abastadas o fato de o filho da patroa dividir a sala de aula com a filha da empregada. A manutenção da ordem econômica depende também de mecanismos opacos, que nos condicionem a reproduzir as segregações nas pequenas atitudes do cotidiano, na maior parte das vezes de maneira inconsciente. 
Na atualidade, há um conjunto de jovens que, criados por creches, vizinhos, tias, avós - distantes de suas mães, que acariciavam os filhos de suas patroas - tiveram acesso a uma educação diferente da de seus pais; uma geração de filhos da ralé que superaram as dificuldades e sobreviveram aos percalços de uma educação pública democratizada sem qualidade e puderam avançar nos estudos. Para Freire, no entanto, esse acesso, por si só, não garante que haja um despertar da consciência crítica desses sujeitos. É necessário que essa formação tenha desvelado para eles os mecanismos de opressão. Há de se questionar o que se entende como natural e compreender as razões histórica e cultural das estruturas sociais. Nosso cenário evidencia que uma pequena elite suprime as forças de resistência de uma enorme camada da população que, por sua vez, aposta seus esforços de superação em seus filhos; estes, quando reunidas as condições necessárias, conseguem suplantar imensas barreiras e escapar da reprodução da condição de existência de seus antepassados explorados.

A eficiência das escolas particulares em "preparar" para o vestibular pode ter falhas, e é onde identificamos o papel dos cursinhos pré-vestibulares, funcionando para treinar os alunos de modo que sejam aprovados no vestibular. Para suprir esse fosso existente entre a escola básica e a universidade pública no Brasil, os cursinhos trabalham com uma enorme quantidade de conteúdos sendo apresentados de maneira estratégica, fazendo uso de técnicas de memorização, para que sejam úteis ao menos no dia do exame, o que possibilita ao aluno ultrapassar uma barreira social importantíssima para a manutenção da ordem social atual.

A eficiência de cada cursinho pré-vestibular em promover mais aprovações reflete-se no valor de sua mensalidade, e isso também reafirma o círculo vicioso de reprodução das desigualdades sociais: o estudante com maior poder aquisitivo poderá arcar com custos de cursinhos eficientes, que garantirão a ele, em algum tempo, uma vaga no ensino superior público ou em universidade particular de excelência, que conferirá a ele status e uma profissão que possibilitará ainda mais poder aquisitivo.

Apartados desse caminho estão os filhos da ralé. Poucos sequer são informados sobre as possibilidades de ensino superior público gratuito e, quando são, 
poucos acreditam na real possibilidade de pertencer a esse espaço, já que, ao observar com cuidado sua realidade, percebem os enormes desafios como barreiras intransponíveis. Esse modo de enxergar não é só um modo particular psicológico de se ver no mundo, mas a consequência da barreira estrutural material necessária para manutenção do sistema social, que afeta da mesma maneira milhares de jovens no Brasil.

Os alunos pobres que alcançam concluir o ensino médio e conhecem a possibilidade de cursar uma universidade podem recorrer a iniciativas de entidades sem fins lucrativos, organizações não governamentais, igrejas, associações, sindicatos, movimentos sociais ou grupos vinculados às próprias universidades que ofereçam aulas preparatórias para os exames. São cursinhos de diferentes nomeações (comunitários, alternativos, populares) cujo fim pode ser apenas ajudar o aluno pobre a ingressar numa universidade, que estão embasados em uma concepção de educação para além do que é o considerado possível, propondo uma formação que questione o próprio vestibular e oferecendo formação humana crítica. Muitos cursinhos populares cumprem esse papel por carregarem a afirmação da categoria popular e assumem o compromisso ético com os oprimidos.

Por algumas variações da sua trajetória existencial, que apesar de condicionada não está determinada, portanto está na ordem do imprevisível, alguns jovens conseguem chegar ao ensino superior público e gratuito e, com isso, podem ter o desejo de mudança, de levar sua trajetória como exemplo para outros jovens pobres. Essa vontade de estender a conquista pessoal ao coletivo é fruto de uma consciência crítica que permite escapar da lógica individualista da meritocracia e perceber a potencialidade do agir em conjunto.

Com esse desejo de mudança e de potencializar a ação coletiva, cursinhos populares são criados nas periferias do país a fim de colaborar para que jovens pobres tenham alguma chance de concorrer a vagas no ensino superior particular com bolsa ou no ensino superior público. Neste artigo, apresentamos uma interpretação àluz do pensamento de Paulo Freire sobre a prática de um cursinho popular localizado na cidade de Itapevi, região periférica da grande São Paulo. A questão que nos move é: O quanto a prática desses cursinhos pode resgatar o pensamento 
de Paulo Freire para a atualidade e preservá-lo da ruína de leituras distorcidas e equivocadas ou do esquecimento?

\section{Paulo Freire, a educação libertadora e o despertar da consciência crítica}

Em Freire, encontramos o conceito de história visto como possibilidade, o que nos permite compreender que nosso posicionamento intervém no futuro que não é, de forma alguma, inexorável, mas sim imprevisível e incontrolável. (FREIRE, 1996).

O conceito de libertação que surge com a Teologia da Libertação tem sua conotação relacionada a práticas concretas de libertação de povos oprimidos em situações em que a crueldade do modelo neoliberal tomava proporções ainda desconhecidas. Anseios e expectativas, movidos por um forte sentimento de esperança e de crítica social, tornaram possíveis transformações na própria Igreja Católica, mais especificamente na América Latina, voltando-se para a luta dos movimentos sociais (GUZZO; LACERDA, 2009).

A fé é convidada a voltar-se para os desafios presentes na realidade e colaborar em sua solução [...] percebemos a grande novidade das lgrejas na América Latina e Caribe: a entrada dos cristãos e cristãs na luta de libertação dos pobres e excluídos. (FERRARO apud GUZZO; LACERDA, 2009, p.42) ${ }^{3}$

Mas, na medida em que o discurso de liberdade e a denúncia dos mecanismos de opressão tomam forma e contornos concretos de interferência no mundo, esse discurso passa a ser perseguido pelos detentores do poder.

Freire aponta, na prática, para uma educação que é a fortaleza dos educadores que acreditam na transformação do mundo, uma maneira crítica de formar e se formar que desvela os mecanismos de exploração e que abre caminhos de luta e de esperança para os sujeitos envolvidos no processo de aprendizagem. É evidente sua relação com as organizações coletivas de luta contra o sistema de exploração capitalista. A ideia de "verdade a ser revelada" que permeia a proposta de uma educação conscientizadora parte da compreensão de que vivemos em um mundo

\footnotetext{
${ }^{3}$ FERRARO, B. A Teologia da Libertação: Ligação Fé - Vida e a Opção Pelos Pobres. In: GUZzO, R.; LACERDA F., Psicologia Social para a América Latina: O resgate da psicologia da libertação. Campinas: Alínea, 2009, cap. 1, p.41-47.
} 
de segregação e exploração, que funda essa exploração na mentira, no silenciamento de discursos opositores e na omissão.

Em Pedagogia da autonomia, Freire (1996) explica que a curiosidade do aluno, que a princípio é ingênua, deve ir aos poucos se transformando em curiosidade epistemológica, pela forma como o aluno se aproxima do objeto de estudo de maneira metódica e rigorosa. Nesse exercício de criticidade, desenvolve-se a consciência para que os alunos possam compreender a complexidade dos fenômenos.

Assim, em última análise, a educação libertadora deve ser compreendida como um momento ou um processo, ou uma prática onde estimulamos as pessoas a se mobilizar ou a se organizar para adquirir poder. (SHOR; FREIRE, 1986, p. 47).

Freire indica que a educação deve ser corajosa, propondo ao povo uma reflexão sobre si mesmo, sobre o seu tempo e sobre as suas responsabilidades. Uma educação que seja capaz de oferecer as possibilidades de refletir sobre o próprio processo de refletir e sobre o que isso significa (FREIRE, 1967). Dessa imersão no processo reflexivo surgiria a capacidade de opção dos sujeitos; assim, nesse sentido, o sujeito inicialmente estaria emumacondição irreflexiva ou denominada de "intransitividade de consciência", característica da imersão em que o sujeito se encontrava inicialmente (FREIRE, 1959). Essas ideias foram publicadas por Paulo Freire inicialmente em uma tese para a Escola de Belas Artes de Pernambuco (FREIRE, 1959) e, posteriormente, em seu primeiro livro no Brasil, "Educação como prática da liberdade" (FREIRE, 1967). Freire (1959) indica que, nesse estado de intransitividade, o ser humano se encontra limitado na sua esfera de apreensão darealidade, na qual, segundo Freire (1967), está impermeável a desafios situados fora de sua esfera biológica, vegetativa. Desse estado, o homem pode, através da reflexão, emergir em um novo estado - o da "transitividade ingênua", no qual se amplia seu poder de captação e de resposta por meio do diálogo. "Seus interessese preocupações, agora, se alongam a esferas mais amplas do que a simples esfera vital". (FREIRE, 1967, p. 60). No entanto, essa consciência transitiva é ingênua num primeiro momento; uma vez que ela apresenta simplicidade na interpretação dos problemas, há uma tendên- 
cia simplista a julgar que o tempo passado foi melhor, subestimar o homem comum e ainda há uma forte tendência ao gregarismo, característica da massificação. Além disso, as argumentações são frágeis, com um forte teor de emocionalidade, e permanecem explicações mágicas sobre os acontecimentos e sobre o ser humano. Para ilustrar a passagem da intransitividade para a transitividade ingênua, relatamos um encontro de Freire com trabalhadores rurais descrito por Valente (2007):

- Muito bem-disse eu a eles - eu sei-Mas vocês não sabem. Mas por que eu sei e vocês nãosabem?

- O senhor sabe por que é doutor. Nós não - exato, eu sou doutor. Vocês não. Mas por que eu sou doutor e vocês não?

- Porque foi à escola, tem leitura, tem estudo e nós, não.

- Por que fui à escola?

- Porque seu pai pôde mandar o senhor à escola. O nosso não.

- E por que os pais de vocês não puderam mandar vocês à escola?

- Porque eram camponeses como nós.

-E o que é ser camponês?

- É não ter educação, posses, trabalhar de sol a sol sem ter direitos, esperança de um dia melhor.

-E por que ao camponês falta tudo isso?

- Porque Deus quer.

-Equem é Deus?

-É o pai de todos nós.

-E quem é pai aqui nesta reunião?

Quase todos, de mãos para cima, disseram que o eram. Olhando o grupo todo em silêncio, me fixei num deles e lhe perguntei - Quantos filhos você tem?

-Três.

- Você seria capaz de sacrificar dois deles submetendo-os a sofrimentos para que o terceiro estudasse, com vida boa no Recife? Você seria capaz de amar assim?

-Não.

Se você - disse eu -, homem de carne e osso, não é capaz de fazer uma injustiça destas, como é possível entender que Deus o faça? Será mesmo que Deus é o fazedor dessas coisas? 
Um silêncio diferente, completamente diferente do anterior, um silêncio no qual algo começava a ser pratejado. Em seguida: Não, não é Deus o fazedor disso tudo. É o patrão. (VALENTE, 2007, p.17).

A transitividade ingênua que se perpetua leva o ser humano a uma consciência fanatizada, como dito por Freire (1967). Esse é um dos perigos, segundo Freire, ao qual o irracionalismo sectário conduz os indivíduos. Para o autor, o problema não está apenas na intransitividade, mas na transitividade ingênua que se perpetua.

Esta transitividade ingênua deve avançar para a transitividade crítica, que pode ser promovida com a educação dialogal e ativa, voltada para a responsabilidade social.

A transitividade crítica tem como característica fundamental a profundidade na interpretação dos problemas, a consciência ética dos sujeitos quando se assumem autônomos e se responsabilizam por suas ações e decisões e se negam a transferir responsabilidades, como nas situações de heteronomia. A criticidade exige abrir mão das "certezas" que cegam e geram preconceitos de toda natureza. Para Luckesi (2011), o ideal seria que o todo da compreensão e da conduta dos sujeitos e de cada pessoa ocorresse de modo crítico, coerente e sistematizado através da reflexão filosófica.

Giroux (2016) aponta que tem havido poucos educadores com o rigor teórico, a coragem cívica e o sentido de responsabilidade moral de Paulo Freire. Para ele, o exemplo de Freire é mais importante agora do que nunca: "[...] a linguagem da crítica e a educação da esperança são o seu legado, que está cada vez mais ausente de muitos discursos liberais e conservadores sobre os problemas educacionais atuais e vias adequadas de reforma." (GIROUX, 2016, p.1). Ainda para Giroux:

Paulo passou a vida guiado pelas crenças de que valia a pena lutar pelos elementos radicais da democracia, de que a educação crítica é um elemento fundamental para a mudança social progressiva, e de que a forma como pensamos sobre política é inseparável daquela como compreendemos o mundo, o poder e a vida moral a que aspiramos. Paulo acreditava firmemente que a democracia não pode durar sem a cultura formativa que a torna possível. Numa altura em que as instituições 
públicas de educação básica e superior estão sendo associadas à lógica do mercado, à conformidade, à perda de poder e a modos inflexíveis de punição, conhecer as contribuições significativas da obra e o legado de Paulo Freire é mais importante do que nunca. (GIROUX, 2016, p. 1).

\section{Cursinho Popular de ltapevi - Uma experiência de educação popular}

Este estudo contou com a generosa participação de um grupo composto de dois professores e duas professoras de um cursinho popular em ltapevi (SP).

O município de Itapevi está localizado na periferia da região metropolitana de São Paulo, bastante distante dos centros laborais e de estudo da maioria de seus moradores. Estes sofrem com a precarização dos recursos para educação, saúde, cultura e lazer. Segundo dados da pesquisa de Mendes (2011), o Índice de Desenvolvimento Humano (IDH) do município é de 0,759, deixando o munícipio em $475^{\circ}$ lugar dentre os 645 municípios do estado de São Paulo. Em relação aos dados educacionais, temos que, dentre a população com 25 anos ou mais, 70, 19\% têm menos de oito anos de estudo.

Oferecer um cursinho de educação popular aos jovens estudantes do ensino médio que não têm possibilidade de fazer um curso pago é um desafio político, ético e social para os educadores envolvidos nesta pesquisa.

A experiência do cursinho popular Chico Mendes surgiu da iniciativa de um grupo de estudantes amigos que, ao saírem do ensino médio na escola pública, se depararam com a muralha simbólica que separa os alunos da escola pública básica dos estudos no ensino superior de qualidade. Dessa forma, tiveram de contar com anos de preparação em cursinho pré-vestibular. Reflexões diversas foram sendo importantes para que surgisse a inquietação a disposição de oferecer, àqueles que ainda não haviam tido contato com o processo seletivo para ingresso na educação superior, um espaço capaz de diminuir a distância entre a escola pública básica e a universidade pública. Assim nasceu o sonho de se unirem para a construção de uma experiência nova de educação: um cursinho popular na cidade.

Quando, aos poucos, esses jovens foram ultrapassando o muro da dis- 
criminação social e chegando ao ensino superior de qualidade, eles começaram a se reunir politicamente para a construção coletiva desse espaço destinado a um novo "fazer educacional". Quando o quadro de professores estava formado, o espaço havia sido negociado e a divulgação estava assegurada, o sonho se fez real e a experiência foi se costurando em meio a muitas dificuldades:

[...] nos reunimos em grupo, a gente fazia diversas reuniões, reuniões que varavam a madrugada, e no trem, espaço de socialização, espaço em que a gente se reunia todo mundo pra ir pra faculdade, um pra USP, outro pra PUC, outro pra Fatec, outros para os cursinhos ainda, e a gente começou a discutir, como que é a educação, que educação que é essa que nós temos, educação, em que nós saímos de escolas públicas e não funcionou, e que nós fomos realmente conhecer, criar prazer em estudar, criar prazer pelo conhecimento, após passar por um cursinho quando a gente começou aprender, e vimos como era o gigantesco da Universidade, com todos os seus problemas também, por ser um espaço meio que restrito e seleto, e não universalizador, universidade que não se universaliza para a sociedade, e a gente começou a questionar e a gente decidiu, vamos construir um cursinho, porque sabemos da necessidade que sentimos e dos alunos iguais a nós que não tiveram oportunidade terão também e que nós podemos contribuir, e nós então decidimos construir esse cursinho, fizemos há quatro anos um projeto inicial e sempre nos questionando também, mas isso também é paliativo, porque a ideia central é uma educação de qualidade que hoje não funciona, e a gente sempre teve essa característica de questionar a própria existência do cursinho, se questionar quanto a educação de qualidade, quanto a avaliação que é feita de modo restritivo também e não construtivo, que é o vestibular, muito segmentativo que você não valoriza a diversidade, você cria uma espécie de conhecimento central, único ali, hierárquico [...] Professor N.

O crescimento pessoal e coletivo que o projeto proporcionou é imensurável. Ainda não houve um acompanhamento de quantos alunos foram aprovados no vestibular, mas isso é apenas um dos compromissos desse cursinho. Além das aulas que abordam os conteúdos exigidos no vestibular, também foram organizados passeios culturais, palestras, debates, rodas de leitura, saraus. Todos esses eventos com grande participação dos alunos.

Um momento importante na história do cursinho foi quando alguns professores começaram a questionar o vínculo com um movimento social para articulação e organização de cursinhos populares, a Rede Emancipa. A vinculação havia 
sido aceita por todos, pois ninguém discordava do fato de a Rede Emancipa ser potencializadora da atuação do cursinho por meio da troca de experiências, da organização, da movimentação em torno da reivindicação à democratização verdadeira do acesso à educação pública e gratuita de qualidade. No entanto, passou a ser questionada quando alguns professores se incomodaram com a significativa atuação de militantes do Partido Socialismo e Liberdade (PSOL) na Rede Emancipa. Esse desconforto tomou maiores proporções quando a coordenação da Rede abriu a discussão acerca do apoio à candidatura de um dos fundadores do PSOL.

O grupo se dividiu. Parte dos professores acreditava na importância da Rede Emancipa para o cursinho, bem como na relevância do papel do cursinho na construção da Rede Emancipa. Entre eles estava um dos fundadores da Rede Emancipa e do Cursinho Popular Chico Mendes, que era militante do PSOL. Outra parte dos professores discordava desde a concepção de educação que se escancarava aos olhos de todos nesse momento: uma concepção segundo a qual o fazer pedagógico é político em si. Esse grupo estava focado em ajudar os alunos a serem aprovados nos vestibulares. Mas havia também os que, mesmo compreendendo a educação como prática política, concordando com a importância da organização e da articulação que a Rede proporcionaria, ainda assim se inquietavam com a ameaça de aparelhamento do cursinho, ou seja, a tomada do controle do cursinho por um grupo partidário. Os dois últimos grupos se uniram em oposição à vinculação do cursinho à Rede Emancipa.

Em decorrência dessa divisão, iniciou-se um período angustiante para professores e alunos, em que a convivência entre os sujeitos que ali atuavam com grande entrega passou a ser desagradável, e o projeto inicial se rompeu em 2010.

O Cursinho Popular Chico Mendes continuou vinculado à Rede Emancipa, e o grupo de professores que se opôs criou um novo cursinho, chamado de Cursinho Popular de Itapevi, que se desfez ao final de um ano por falta de recursos materiais e consequente desmotivação do grupo. Alguns professores que tiveram essa experiência passaram a se envolver em práticas culturais e educativas com a comunidade de maneira independente. E alguns retornaram ao cursinho Chico Mendes para dar aulas, ignorando as pautas partidárias. 
A investigação relatada neste artigo foi realizada com os professores que se opuseram à vinculação e que, no entanto, partilhavam os ideais dos seus colegas educadores que permaneceram na Rede Emancipa, pois o que os dividia eram discordâncias acerca dos meios para alcançar os objetivos. Esse grupo sempre apresentou grande insistência em garantir autonomia, fortalecido na carta de princípios norteadores do Cursinho Popular Chico Mendes: "O Cursinho Popular é independente e autônomo a todos partidos e a qualquer organização política"4.

\section{Procedimentos metodológicos}

Neste trabalho de pesquisa, a perspectiva qualitativa não considera a possibilidade sequer de o pesquisador possa observar os seus "objetos" de pesquisa, em uma concepção epistemológica cientificista e positivista. Para Bicudo $(2000 ; 2011)$ parece que, para os pesquisadores que assumem essa postura, a qualidade seria do "objeto" e passível de ser observada. Para que este estudo tivesse coerência interna, optamos por declarar os fundamentos que permitem construir a nossa prática de pesquisa, assim assumimos que, do ponto de vista filosófico, este trabalho e a nossa prática educativa seguem a filosofia fenomenológica de Maurice Merleau-Ponty, como a visão fenomenológica do Eu-Tu, de Martin Buber (2010); a concepção epistemológica da Biologia do Conhecer, de Humberto Maturana (MATURANA, 2006), ; e, do ponto de vista educativo, a Pedagogia de Paulo Freire (FREIRE, 1967; 1992; 1996; 2005; 2007).

Nesta concepção filosófica, epistemológica e pedagógica, não é possivel olhar para o sujeito fora da sua história, das suas experiências, das suas relações e do seu corpo. Da mesma forma deve ser compreendido o papel do pesquisador. Um e outro provocam perturbações recíprocas, estando juntos presentes no mundo. Assim, pesquisador e pesquisado fazem parte do mundo e não é possível estudar os sujeitos fora do mundo.

${ }^{4}$ A carta de princípios norteadores do Cursinho Popular Chico Mendes pode ser acessada na página: https://cpchicomendes.wordpress.com/about/ 
Temos, assim, que o mundo está abarcado pela consciência e o que há não está fora dela. Isso significa que o fenômeno investigado não é concebido como um objeto que está dado em um mundo exterior ao do sujeito pesquisador. Isto é, para que o mundo possa ser conhecido, ele está-como-sujeito, é efetuado por um sujeito que está situado no "mesmo" mundo do fenômeno. (SEIDEL; ROSA, 2014, p. 408).

A matriz da reflexão e da experiência é o mundo em que os sujeitos vivem (MERLEAU-PONTY, 2018) e, nessa concepção fenomenológica, não é possível apenas estudar as palavras como entes isolados: as palavras são ditas por um corpo, que é um sujeito em um momento histórico, e são ouvidas por outro sujeito. A intersubjetividade e a subjetividade ocorrem com o ser-no-mundo.

Dessa forma, neste trabalho, a escolha da fenomenologia de Maurice MerleauPonty e Martin Buber para uma reflexão existencialista não prioriza os sujeitos nem os objetos, mas a absoluta indissociabilidade de um aspecto e outro na própria estrutura da vivência da experiência intencional (BRUNS, 2000).

\section{Resultados e discussão da experiência}

A orientação inicial para a discussão foi de que os participantes falassem um pouco sobre o que os move em direção à prática educacional. Todos iniciaram suas falas relatando suas trajetórias como estudantes até alcançarem a universidade e se comprometerem com o fazer educacional:

[...] pra mim foi muito, muito difícil, mesmo porque pegava o trem, chegava na faculdade, encontrava com pessoas que iam pra faculdade de motorista, uma coisa totalmente fora da minha realidade, e enxergava essas pessoas com reais possibilidades, elas acreditavam de verdade nas possibilidades que elas tinham, porque a forma de ver até então foi totalmente o inverso da minha, que sempre fui criada sendo embutido na minha cabeça que eu não podia, que eu não podia, que eu não podia, e lá eu vivendo a mesma realidade, [...], que é "você tá aqui, mas a gente não quer você aqui, você tá aqui, mas meio que como intruso. (Professoras).

Daí eu passei, segundo ano do cursinho eu passei, foi uma felicidade total, mas aquela coisa de entrar na faculdade e aquilo não fazer parte da minha realidade, e u sempre tive um problema social dentro da minha casa, sempre fui uma sonhadora, quer dizer, pensar coisas que não existiam para mim [lágrimas e comoção de todos]. Aquela coisa assim: aquele mundo não faz parte do mev e por que que eu quis isso? Tanto que eu estava numa aula de latim clássico e aquilo não entrava na minha cabeça e eu chorei, desabei na aula, numa sala de cem alunos, eu comeceia chorar. (ProfessoraM). 
A emoção de uns descortinou a dos outros mais de uma vez, pois suas trajetórias foram comuns no que se refere à resistência aos muitos mecanismos de exclusão simbólicos que atuavam para fazê-los desistir de ocupar esse lugar tão almejado.

O processo de conscientização é doloroso na medida em que escancara o sofrimento de uma sociedade desigual e injusta e exige-se do sujeito experimentar as consequências dessa desigualdade, seja por meio da aproximação com a experiência dos excluídos, seja pela própria experiência de se reconhecer como excluído.

É importante salientar que o processo de conscientização não se encerra no desvelar da realidade, mas deve seguir para a transformação desta, o que exige, por parte do sujeito, uma opção reflexiva e crítica que vai ao encontro da compreensão da vocação ontológica do ser humano para o "ser mais", vocação esta que não se realiza de forma plena no indivíduo, apenas, mas no ser humano como ser social.

[...] pensando no cursinho e no problema da gente ter essas contradições, que é essa falta de acesso ao ensino público de qualidade, "questão social", e a característica de tentar quebrar essa barreira e tentar impedir que os lugares sociais sejam sempre determinados por outrem, e volto de novo, de que as pessoas sejam sujeito[s]. (Professor R).

Ou seja, a gente, como sempre dá apoio a isso, do aluno se manifestar, dele conseguir enxergar essas formas de autoritarismo, essas questões que se refletem no micro da escola, mas que se refletem no todo da sociedade, e dele tentar participar para mudar isso. (Professor N).

A conscientização desvela a ação mitificadora que impede os seres humanos de pensar, de questionar as razões de ser das coisas, essa ação típica dos dominadores deve ser denunciada por aqueles sujeitos que fazem a opção pelos excluídos.

O compromisso ético com os oprimidos ocorre no processo de conscientização. Há a perturbação do sujeito, desajustando-o do mundo e conduzindo-o à ação transformadora, caso contrário ele será levado à culpa da qual resultam assistencialismos e filantropia, em busca de uma paz que não existe na ausência de compromisso com a Iuta pela libertação (OLIVEIRA; CARVALHO, 2007).

E assim, ninguém vai me dizer que eu não posso! Então essa coisa de eu falar, e isso é uma coisa que eu quero falar para os alunos do cursinho e onde eu tiver que dar aula: É possível! Mas como? Vou te dar alguma teoria, mas mais do que teoria, tem algo dentro de você! Tem algo dentro de você! (Professora M). 
[...] como funciona esse discurso que diz "vamos atender a comunidade, vamos servir a escola, vamos abrir a escola para que todo mundo tenha acesso"? Não está aberta! A gente está com um projeto político, público, social, aqui e não está aberta para a gente. E a gente vai sempre com a questão de exigir o direito, queremos usar o espaço da escola, nada mais, dentro da secretaria e eles transferem essa questão do direito como se fosse algo como um benefício particular, 'eu sendo uma pessoa influente, eu sendo um vereador, eu sendo prefeito, eu sendo isso, eu consigo the garantir esse direito, ou melhor, eu consigo lhe garantir esse benefício, eu faço essa caridade pra vocês', mas isso colocando o meu lado pessoal como se partisse de mim, o que é um direito, você transforma como se fosse uma vontade particular, e não é isso que a gente quer, a gente quer que se valha a questão dos direitos. (Professor N).

O comprometimento dos educadores com uma sociedade mais justa e solidária exige uma prática que, ao mesmo tempo que denuncia a lógica exploratória do capital, anuncia a esperança. A prática denunciadora da opressão e anunciadora da esperança na transformação é a própria prática da educação libertadora que propôs Freire, na qual educador e educando podem ousar inventar um jeito novo de conviver.

Mas além de trazer os alunos, irem a campo, conhecerem escolas que eles nunca tinham conhecido, por exemplo, ocupar o espaço público, ao mesmo tempo a comunidade fica conhecendo [...], o cursinho tem alguma visibilidade, então, quando propus, eu pensei em aliar essas duas coisas, a gente ao mesmo tempo fazer uma prática que promova uma conscientização, uma ingerência e participação, mas não só por parte dos alunos, por parte também da comunidade, que vendo o cursinho pode ocupar aquele espaço e querer que ele esteja lá, por exemplo, seria até uma forma de gerar uma demanda, gerar não, tornar visível essa demanda. (Professor R).

Fundamental para o trabalho do educador em busca da liberdade é a reflexão crítica sobre a própria prática. O senso crítico deve ser útil para que o educador se auto avalie, buscando renovar sua prática, visto que é a formação permanente do educador, por meio da reflexão crítica, que possibilita sempre poder melhorar. Como diz Freire em Pedagogia da autonomia (1996): "O próprio discurso teórico, necessário à reflexão crítica, tem de ser de tal modo concreto que quase se confunda com a prática".

Eu acho que esse foi um dos pontos que a gente mais pecou até hoje em relação aos alunos, na nossa proposta de ensino... não sei se vocês concordam comigo, porque, por exemplo, as reuniões, geralmente, não sei se convocavam, mas não tinha aluno, os alunos não participavam das reuniões do cursinho, só que na prática, por esse lado numa questão mais prática deles, propor coisas que eles fizessem. (Professor R). 
É, não tanto na prática, mas de certa forma, assim, só para tentar não ser injusto, a gente fez uma prática pelo discurso, pelo menos, é que às vezes tem essa discussão de discurso como prática, e prática como discurso, a gente fez a nossa prática na sala de aula. E eu acho que a gente já pode visualizar que algum efeito teve, eu não sei mensurar nem se isso foi efeito do cursinho, mas, por exemplo, no Paulo de Abreu [escola pública onde funcionou o cursinho por um tempo], foram alunas que foram falar com a direção, então essas alunas tomaram a iniciativa e conseguiram um espaço para todo um coletivo, ajudaram a conseguir esse espaço. (Professor R).

No grupo de professores participantes, percebe-se uma grande preocupação em guiar os alunos rumo à autonomia. Trata-se de um trabalho de educadores que, em sua prática, estimulam o senso crítico dos alunos, de modo que passem da curiosidade ingênua para a curiosidade epistemológica, através da reflexão sobre as "certezas" que lhes são apresentadas no processo educacional tradicional. O respeito à autonomia dos alunos como sujeitos é imperativo ético de forte presença nas falas desses educadores:

Uma das nossas maiores angústias é a gente tentar construir com os alunos uma autonomia deles, um hábito assim, para eles buscarem o conhecimento, estudarem, uma reflexão por parte deles mesmo, deles serem autônomos... Porque muitas vezes quando os alunos saem da escola, eles não têm essa cultura, eles têm uma cultura de passividade total, ele espera por conta de que as aulas vão resolver o problema dele, que ele vai pegar tudo pelas aulas, todo o conhecimento que ele pode adquirir [...] , e a participação dele... E nós, sempre, tentamos colocar isso pra eles: 'O que vocês têm aqui no cursinho é muito pouco, vocês têm que buscar muito por fora, estar ligado com o que acontece no seu entorno, e buscar participar, começar a enxergar a realidade que os cerca para vocês poderem atuar! (ProfessorN).

A busca por recuperar nos seres humanos sua vocação em ser sujeito da ruptura, da opção, seres que julgam, estabelecem objetivos, imprimem ação e refletem criticamente sobre ela é uma busca daqueles que têm esperança, que sonham e cujo sonho é situado na práxis.

[...] o nosso interesse é que o aluno passe no vestibular, mas muito mais do que isso, é que o aluno tenha um senso crítico, não é só a questão do vestibular em si, mas muito mais do que isso: a gente quer que ele tenha esse senso crítico nele, é aquela coisa, do sujeito se constituir através do olhar do outro, então eu acredito que aqui no cursinho eles se constituem, porque eles começam a perceber, olha a M., subindo na cadeira com o Velho do Restelo [da obra Os Lusíadas de Luís Vaz de Camões] tinha uma voz, ainda que ninguém estivesse dando razão a ele é uma voz profética, na literatura você vê ali que é uma voz profética, então, ela começa a ver que se um velho que ninguém estava dando atenção conseguiu fazer, então trabaIhando as questões sociais, fatos históricos, enfim, todas as disciplinas, eu 
acho que o que eu mais vejo no cursinho é isso, os alunos estão se constituindo como sujeitos, eles estão vendo que eles são agentes, eles estão vendo que eles têm um papel dentro da sociedade muito mais do que estarem prontos para fazer uma prova de vestibular. (Professora M).

É mediante a valorização do diálogo e da narração da própria experiência que esse grupo de educadores consegue ensinar os alunos com amor e prazer. A identificação dos alunos com os educadores, como exemplos da prática que desejam assumir para si, permite o aprendizado com sentido. Essa identificação pode se dar por diversos motivos, entretanto a origem e a trajetória desses educadores - que dão o próprio testemunho do impossível que historicamente se faz possível, tornando o futuro problematizável-certamente são essenciais para a disposição dos alunos em aprender.

[...] impressionante como isso tem impacto a nossa vida, assim, porque [...] o curso que eu faço e as pessoas que eu encontro, e com quem eu convivo, melhorou bastante a minha forma de enxergar o mundo e de atuar nele e de me entender como pessoa e cidadão, e não é só para mim. (Professor R).

Eu mesmo assisti [às] aulas do N, [...] eu ficava maravilhado, aulas dele falar sobre..., e ele problematizar na aula, aquela aula sobre distribuição de terras no Brasil, aquela aula que a J. que foi boia-fria, dev o depoimento dela [...]. Eu achei fantástico, fantástico, porque por mais que seja algo passado, mas trouxe a vivência, uma experiência, alheia a alguns alunos. (Professor R).

Para um fazer educacional novo, é necessário ousadia e criatividade. É preciso superar o senso comum pedagógico, ultrapassar os limites impostos pelo velho modo de pensar educação e assumir os riscos de ir além, com uma prática renovada, uma experiência que rompa com a lógica da exploração. Essas diferentes experiências educacionais preparam os jovens e tornam o ambiente escolar mais fecundo a novidades que orientem a ação política em busca de uma nova forma de se organizar socialmente.

[...] que a gente sempre quis questionar a própria existência, questionar o vestibular e lutar por uma educação de qualidade é esse nosso ideal assim, nosso potencial de fazer educação de qualidade. (Professor N).

E eu acho que assim, citando até um pouco o Freire, é lógico que tem todas as discussões e eu acho que tem que se fazer uma crítica mesmo, mas até pensando a Educação de Jovens e Adultos como ele parte do TI -JO -LO, não é só para jovens e adultos, não é, sabe? Porque, se você não faz essa ligação com a vida com o cotidiano, fica muito abstrato, muito longe... porque uma coisa que a Hannah Arendt fala é que, se não você 
perde o mundo comum, sem o mundo comum você só está reforçando anfragmentação que a gente vive hoje, então, se você não combater a fragmentação, além das relações sociais entre as pessoas, não tem como fazer educação, não tem como educar, nem aprender fragmentado. (Professor R).

Esses professores comprometidos com um cursinho popular de periferia questionam a existência e as finalidades do próprio cursinho e constroem uma luta por democratização da educação de qualidade. Esses jovens educadores de maneira alguma deixam de ensinar, ensinar aquilo que é preciso saber para alcançar o conhecimento através do ensino superior, mas isso não é feito na superficialidade, e sim no debate da essência do problema do acesso. O diálogo intenso durante o grupo focal mostrou novas possibilidades que foram sendo vislumbradas por esses educadores. Nesse sentido, formar professores na perspectiva freireana significa contribuir para a formação de sujeitos com compromisso político.

Muitos cursinhos populares cumprem esse papel de ação política, bem como o papel de manter a atualidade político-pedagógica do pensamento de Paulo Freire. Ao carregarem a afirmação da categoria popular, assumem o compromisso ético com os oprimidos e mantêm acesa e atual a chama da pedagogia freireana.

\section{Considerações inacabadas}

A situação de intervenção na realidade vivenciada pelos professores que participaram do grupo focal evidencia que a formação pedagógica de professores, através das licenciaturas não deveria deixar de lado a formação política dos seus alunos. $O$ debate e a problematização devem chegar à essência, desvelar as verdadeiras razões de ser dos problemas, e não "psicologizá-los", isolá-los, particularizá-los, como é de costume em discussões em que se pretende a neutralidade, a imparcialidade, cujo caráter é sempre de reafirmar o discurso dominante. É nesse sentido que a licenciatura deveria ser responsável também pelo conteúdo político da formação do educador, além de fortalecer suas reflexões sobre ética, políticas educacionais, economia, filosofia, debater a essência dos problemas da escola, favorecendo a atuação do professor como construtor de um projeto de educação que é essencialmente político. 
Concordamos com SANTOS e BARRETO (2011) quando afirmam que, diante do processo histórico de repressão, com a ditadura militar no Brasil, é compreensível que se enfatizasse com intensidade a formação política de professores através do partidarismo; no entanto, é fundamental a noção de que a política não se pode estar centralizada apenas no processo de militância partidária, posto que a ação pedagógica, em si, nas salas de aula formais ou não formais, também se constitui numa ação política no sentido mais amplo.

É evidente que o esvaziamento da política é um problema que é fruto da própria condição humana no mundo moderno. A busca pela neutralidade e a repulsa à vida pública e política têm resultado no absurdo crescimento do poder do mercado sobre nossas vidas.

A escola vista como um projeto político que se afirma como direito de todos pode significar oportunidade para a transformação da condição social dos sujeitos. Ainda que essa transformação esteja restrita à obtenção de um bom emprego e ao acesso ao consumo, não se pode ignorar o impacto disso em uma enorme massa de famílias excluídas, abandonadas pelo Estado, que somente a partir da escolarização é que têm alguma chance de ampliar seu capital cultural.

Não se pode ignorar, sobretudo, que os educadores dos filhos dessa ralé, quando conscientes disso, podem estimular nesses jovens o desejo de superação de barreiras, e provocá-los a refletir, para que caminhem em direção ao despertar da consciência de que as relações de desigualdade não estão dadas pela natureza, mas sendo construídas historicamente - e por isso elas podem ser questionadas e reinventadas. A educação pode, ainda que diante de uma gama enorme de fatores restritivos, promover a segurança que faça um jovem da periferia olhar para si próprio com confiança, desprendendo-se de qualquer culpa que a meritocracia tenha nele implantado, enxergando-se na sua total potencialidade, que só se realiza na ação coletiva.

Muitos professores da educação popular em cursinhos também atuam nas escolas públicas e, por meio desse intercâmbio, a educação popular tem contribuído de maneira fundamental para que a escola pública se reconfigure como um espaço de ação em conjunto, onde surjam novas formas de interação e intervenção no mundo. 
Por seus princípios democráticos e dialógicos, os professores comprometidos com a educação dos marginalizados abrem espaço para a fala e para a ação, mas antes apresentam aos seus alunos o mundo, possibilitam que se reconheçam como parte deste e sejam acolhidos por este mundo, de tal modo que queiram lutar por ele.

\section{Referências Bibliográficas}

BICUDO, M. A. V. A pesquisa qualitativa fenomenológica à procura de procedimentos rigorosos. In BICUDO, M. A. V. (org.). Fenomenologia: confrontos e avanços. São Paulo: Cortez, 2000. p. 71-102.

BICUDO, M. A. V. A pesquisa qualitativa olhada para além dos seus procedimentos. In BICUDO, M. A. V. (org.). Pesquisa qualitativa segundo a visão fenomenológica. São Paulo: Cortez, 2011. p. 11-28

BRUNS, M. A. T. Reflexões sobre o "fazer" metodológico. In: CASTRO, D. S. P.; ÁZAR, F. P.; PICCINO, J. D.; JOSGRILBERG, R. S. (orgs.) Fenomenologia e análise do existir. UMESP, São Paulo, 2000.

BUBER, M. Eu e tu. 4. reimp. São Paulo: Centauro, 2010.

DOWBOR. L. A era do capital improdutivo: por que oito famílias têm mais riqueza do que a metade da população do mundo? São Paulo: Autonomia Literária, 2017.

FREIRE, P. Educação como prática da liberdade. Rio de janeiro: Paz e Terra, 1967.

FREIRE, P. Educação e atualidade brasileira. Tese de concurso para a cadeira de História e Educação. Escola de Belas Artes de Pernambuco, Recife, 1959. Disponível em: http://acervo.paulofreire.org:80/xmlui/handle/7891/1976. Acesso em: 19 fev. 2020 .

FREIRE, P. Pedagogia da autonomia: saberes necessários à prática educativa. Rio de Janeiro: Paz e Terra, 1996.

FREIRE, P. Pedagogia da esperança. 16. ed. Rio de Janeiro: Paz e Terra, 1992. 
FREIRE. P. Pedagogia do oprimido. Rio de Janeiro: Paz e Terra, 2005.

FREIRE, P. Política e educação. 8. ed. São Paulo: Villa das Letras, 2007.

GARCÍA-HUIDOBRO, J. E. Educación liberadora. In: SALAS, R. Pensamiento crítico latinoamericano: conceptos fundamentales. Santiago de Chile: Ediciones Universidad Católica Silva Henríquez, 2005. p. 227-237.

GIROUX, H. A. Pedagogia crítica, Paulo Freire e a coragem para ser político. Revista e-Curriculum, São Paulo, v.14, n.01, p. 296 - 306 jan./mar.2016 Programa de Pósgraduação Educação: Currículo - PUC/SP. http://revistas.pucsp.br/index.php/curriculum

GIROUX, H. A. Professores como intelectuais transformadores. In: GIROUX, H. A. Os professores como intelectuais: rumo a uma pedagogia crítica da aprendizagem. Porto Alegre: Artes Médicas, 1997. p. 157-164.

GUZZO, R. S. L; LACERDA, Jr. F. (org.). Psicologia social para a América Latina: o resgate da psicologia da libertação. Campinas: Alínea, 2009

LUCKESI, C. C. Filosofia da educação. 3. ed. São Paulo: Cortez, 2011.

MATURANA, H. Biologia do fenômeno social. In MAGRO, C.; GRACIANO, M.; VAZ, N. (org.). A ontologia da realidade. Belo Horizonte: Editora da UFMG, 2006. p. 196-209.

MENDES, M. T. Inclusão ou emancipação? Um estudo do Cursinho Popular Chico Mendes/Rede Emancipa na Grande São Paulo. 2011 . 135 f. Dissertação. (Mestrado em Educação). Faculdade de Educação da Universidade Federal do Rio Grande do Sul, Rio Grande do Sul, 2011.

MERLEAU-PONTY, M. Fenomenologia da Percepção. $5^{\circ}$ ed. São Paulo: Martins Fontes, 2018.

MESZÁROS, I. A educação para além do capital. 2. ed. São Paulo: Boitempo, 2008.

OLIVEIRA, P. C.; CARVALHO, P. A intencionalidade da consciência no processo educativo segundo Paulo Freire. Paideia [versão eletrônica], Ribeirão Preto, v. 17, p. 219-230, 2007. Disponível em:

http://www.scielo.br/pdf/paideia/v17n37/a06v17n37.pdf. Acesso em:27 ago. 2008. 
SANTOS, C.P.; BARRETO, R.P. Formação de professores como compromisso político. Metáfora Educacional [versão Eletrônica], n.10, jun. 2011. Disponível em:

http://www.valdeci.bio.br/revista.html. Acesso em: 28 out. 2012.

SEIDEL, D. J.; ROSA, M. Possibilidades da percepção fenomenológica nos procedimentos investigativos da pesquisa qualitativa em educação matemática. Educ. Matem. Pesq. São Paulo, v. 16, n. 2, p. 407-428, 2014.

SETTON, M. G. J. A teoria do habitus em Pierre Bourdieu: uma leitura contemporânea. Faculdade de Educação da Universidade de São Paulo, 2002. Disponível em: http://www.scielo.br/pdf/rbedu/n20/n20a05. Acesso em: 5 jul. 2017.

SHOR, I.; FREIRE, P. Medo e ousadia: O cotidiano do professor. São Paulo: Paz e Terra, 1986.

SOUZA, J. A construção social da subcidadania: para uma sociologia política da modernidade periférica. 2. ed. Belo Horizonte: Ed. da UFMG, 2012.

VALENTE, I. Paulo Freire vive: hoje dez anos depois. Folheto de divulgação. São Paulo: Assessoria do mandato Ivan Valente PSOL, 2007. 